\title{
Bone marrow mesenchymal stem cells help heal chronic patellar tendinopathy
}

Gil Rodas

Robert Soler

Joan Rius-Tarruella

Xavier Alomar

Ramon Balius

Lluís Orozco

Lorenzo Masci

Nicola Maffulli

\section{Video Abstract}

Keywords: regenerative medicine, mesenchymal stem cell, patellar tendinopathy, platelet-rich plasma, tendinosis, stem cell therapy, bone marrow, chronic patellar tendinopathy, rehabilitation, physical therapy, sports medicine, clinical study, tendon, knee injury, jumper's knee, patellar tendonitis, leukocyte-poor platelet-rich plasma, ultrasonography, MRI, The American Journal of Sports Medicine

Posted Date: October 14th, 2021

DOI: https://doi.org/10.21203/rs.3.rs-969328/v1

License: (a) This work is licensed under a Creative Commons Attribution 4.0 International License. Read Full License 


\section{Abstract}

Patellar tendinopathy, or jumper's knee, is a common injury in athletes of all skill levels. Aside from causing pain and dysfunction, the condition can be costly for individuals and sports teams. Physical therapy is critical, but consistently effective treatment regimens remain elusive. Regenerative therapy is one promising alternative, as platelet-rich plasma injection and cultured stem cell injection have been shown to repair other types of damaged tissue. To explore the benefits for jumper's knee, researchers compared these two treatments in patients with patellar tendinopathy. The findings, reported in _The American Journal of Sports Medicine_, suggest that cultured stem cell injection is a particularly promising option for functional and structural healing. The researchers examined 20 male patients with patellar tendinopathy that had lasted for at least 4 months, was unresponsive to nonsurgical treatments, and featured lesions larger than $3 \mathrm{~mm}$. The patients all received injections in their patellar tendons: ten received cultured mesenchymal stem cells from bone marrow, while 10 received leukocyte-poor plateletrich plasma. All patients then participated in identical exercise-based rehabilitation programs, and outcomes were measured over a period of 6 months. According to patient questionnaires, both treatments were equally and significantly effective in reducing knee pain and improving knee function during athletic activities. In addition, both treatments were well tolerated. However, imaging via 2-D ultrasonography, ultrasound tissue characterization, and MRI revealed that only cultured stem cell injections significantly improved tendon structure over the 6-month period-plasma injections did not. It's currently unclear if the cultured stem cells exerted their healing effects by differentiating into tendon cells, by secreting paracrine factors, or through another mechanism altogether. Interestingly, the equivalent pain-relieving effects of the two therapies suggest that a treatment does not necessarily need to restore the structure of the patellar tendon to relieve pain and promote functional recovery. Additional follow-up is underway to clarify whether the plasma can elicit structural changes like the cultured stem cells beyond the limited 6-month time frame. Patients who respond suboptimally to plasma will be offered cultured stem cells in a subsequent phase, and further studies with more patients, including female participants and additional athletes, will be completed. Despite its limited size and duration, this study suggests that both treatments are safe and effective for chronic patellar tendinopathy. In combination with physical therapy, leukocyte-poor platelet-rich plasma injection is a good option for pain relief; however, cultured mesenchymal stem cell injection could be a viable option for both pain relief and tissue regeneration. 